\title{
Analysis of microearthquake data at Cold Lake and its applications to reservoir monitoring
}

\author{
Masatoshi Miyazawa ${ }^{1}$, Anupama Venkataraman ${ }^{2}$, Roel Snieder ${ }^{1}$, and Michael A. Payne ${ }^{2}$
}

\begin{abstract}
More than four months of continuously recorded microearthquake data acquired at Cold Lake, Canada, was analyzed using advanced algorithms for microearthquake location and subsurface tomography. Robust determination of the spatial, temporal, and magnitude distribution of seismicity is the first step toward understanding the relationship between the stress perturbations caused by the cyclic steam stimulation (CSS) process and seismicity. Acquisition geometry was constrained because the receivers were located in a single vertical borehole. Despite this constraint, we were successful in improving event locations by use of the double-difference method, which highlights several tight event clusters. The deep cluster at a depth of $400 \mathrm{~m}$, just above the oil reservoir, shows very high seismicity during the CSS processes. A second cluster is observed at shallower depths in the successive steam cycle. This suggests that repeated steaming causes the deformation to spread to shallower depths. The number of events, however, decreases in the second steam cycle. Even though some of the largest events occur below the Clearwater reservoir, we observed few events in the reservoir itself, indicating that the reservoir may be an aseismic region. The size and distribution of seismicity during the first cycle agrees with a Mohr's circle analysis using simple geomechanical modeling.
\end{abstract}

\section{INTRODUCTION}

Pore-pressure changes caused by injection and production of fluids in a producing field perturb the ambient stress field to trigger brittle failure on small fractures or faults, resulting in microearthquakes. Monitoring this induced seismicity can help us understand the mi- gration of the fluid front, and the stress and strain changes in the reservoir and overburden (e.g., Shapiro et al., 2002; Parotidis et al., 2004; Ake et al., 2005; Shapiro et al., 2005).

Induced earthquakes are a consequence of human activity, as opposed to natural earthquakes that are driven by tectonic stress changes. Induced seismicity has been studied in mines, geothermal fields, and in hydraulic fracture stimulation, but is an emerging technology in producing fields. Moreover, most analyses of induced seismicity are confined to microearthquake detection and location, with little or no integration with the geomechanics and in situ stress state of the region.

We analyzed a microearthquake data set from Cold Lake, Alberta, where heavy oil is extracted using the cyclic steam stimulation (CSS) process. Steam at high pressure (about 10-12 MPa) and high temperature (about $300{ }^{\circ} \mathrm{C}$ ) is pumped into the reservoir at depths of about $450 \mathrm{~m}$ to reduce the viscosity of bitumen. The resulting fluid can flow and is pumped to the surface. The CSS process produces microearthquakes or microseismic events (henceforth referred to as events) in the overburden and possibly in the reservoir as well. Talebi and Boone (1998) and Talebi et al. (1998a; 1998b; 1998c) studied the seismicity and casing failure in the production wells at Cold Lake, and theoretically analyzed the possible failure mechanisms. More recently, McGillivray (2005) used induced microearthquake data to monitor steam-front diffusion in the Peace River deposit. In his study, he observes microearthquakes in the reservoir sands. However, the potential for fractures and microseismicity in such unconsolidated reservoir sands is still poorly understood.

Delineating fractures and faults in the reservoir and overburden would help address questions related to the possible occurrence and mechanism of brittle fractures in the oil reservoir and overburden. This requires accurate event location. Hence, we relocated the induced seismicity in one of the Cold Lake pads using the double-difference (DD) method (Waldhauser and Ellsworth, 2000). We also used a simple geomechanical model to understand the relationship between stress changes during steam injection and seismicity.

Manuscript received by the Editor 11 August 2007; revised manuscript received 6 January 2008; published online 5 May 2008

${ }^{1}$ Colorado School of Mines, Center for Wave Phenomena, Golden, Colorado, U.S.A. E-mail: linen@eqh.dpri.kyoto-u.ac.jp; rsnieder@mines.edu.

${ }^{2}$ ExxonMobil Upstream Research Company, Houston, Texas, U.S.A. E-mail: anupama.venkataraman@exxonmobil.com; michael.a.payne@exxonmobil .com.

(C) 2008 Society of Exploration Geophysicists. All rights reserved. 


\section{DATA AND ACQUISITION GEOMETRY}

Microearthquakes at Cold Lake are recorded by eight 3-C geophones that are cemented into a dedicated monitoring well located on each pad (Figure 1). Deployment of the array is mandated by regulatory authorities for the detection and prevention of fluid incursion in the overlying shale and aquifers. It also serves as a secondary detection system for casing failures. The array was not designed to monitor the reservoir for steam conformance.

\section{RELOCATED HYPOCENTERS AND REFINED VELOCITY STRUCTURES}

\section{Traveltime and hodogram analysis}

We analyzed about four months of continuously recorded data that were collected during the first and second steam cycles on pad L08 at Cold Lake. During the production cycle, only microseismic events exceeding a minimum amplitude threshold (triggered data) were acquired. The data were recorded at a sampling frequency of $2 \mathrm{kHz}$ on $12-\mathrm{Hz}$ geophones, resulting in a total volume of about 1.8 TB. More than $90 \%$ of the data consist of noise generated by human and/or machine activity at the surface or in the wells.

Using a method based on a short-term average/long-term average (STA/LTA) algorithm (Earle and Shearer, 1994), we detected 665 events. Of these, 318 events have clear P- and S-wave arrivals on more than one geophone. Preliminary event locations were determined by performing a grid search using traveltime picks and hodogram analysis (Figure 2a). These locations have large uncertainties (tens of meters) and the resolution is poor $(5 \mathrm{~m}$ in horizontal and $10 \mathrm{~m}$ in vertical directions), where the resolution is the average error in the estimated source location when the data would be free of errors. Before we could use these event locations to interpret the seismicity distribution, we had to improve both the location accuracy and resolution. We also determined event magnitudes (Figure 3) assuming a Brune $(1970,1971)$ earthquake source model.

\section{Methods}

We relocated the initial hypocenters using a DD method (Waldhauser and Ellseworth, 2000), which is a powerful method for obtaining accurate event locations when microearthquakes occur in dense seismic clouds. In the DD method, we chose neighboring events where the distance between the events is sufficiently small compared to the length of raypaths to an observation station. The method minimizes a DD that is given by a residual of $\Delta T^{\mathrm{cal}}-\Delta T^{\mathrm{obs}}$, where $\Delta T^{\mathrm{cal}}$ is the traveltime difference calculated using the initial location and the initial velocity model, and $\Delta T^{\mathrm{obs}}$ is the observed traveltime difference. The DD constrains the relative locations of neighboring events. In a seismic event cluster, we can choose any combination of two events. As a result, the final spatial event distributions becomes much clearer than the initial ones.

We modified and used the original program, hypoDD, by Waldhauser (2001) for the double-difference relocation. In the original source code, the observation stations are assumed to be located on the surface, whereas our observation array is in a vertical well. We changed the original coordinate system into a cylindrical system, where we fixed the back-azimuths from the sources. We also considered layered-velocity structures for both $\mathrm{P}$ - and $\mathrm{S}$-waves independently, which made it possible to use a different $V_{\mathrm{P}} / V_{\mathrm{S}}$ ratio at each depth. Between two neighboring layers with large velocity contrasts, we included a buffer zone with multiple layers, in which the

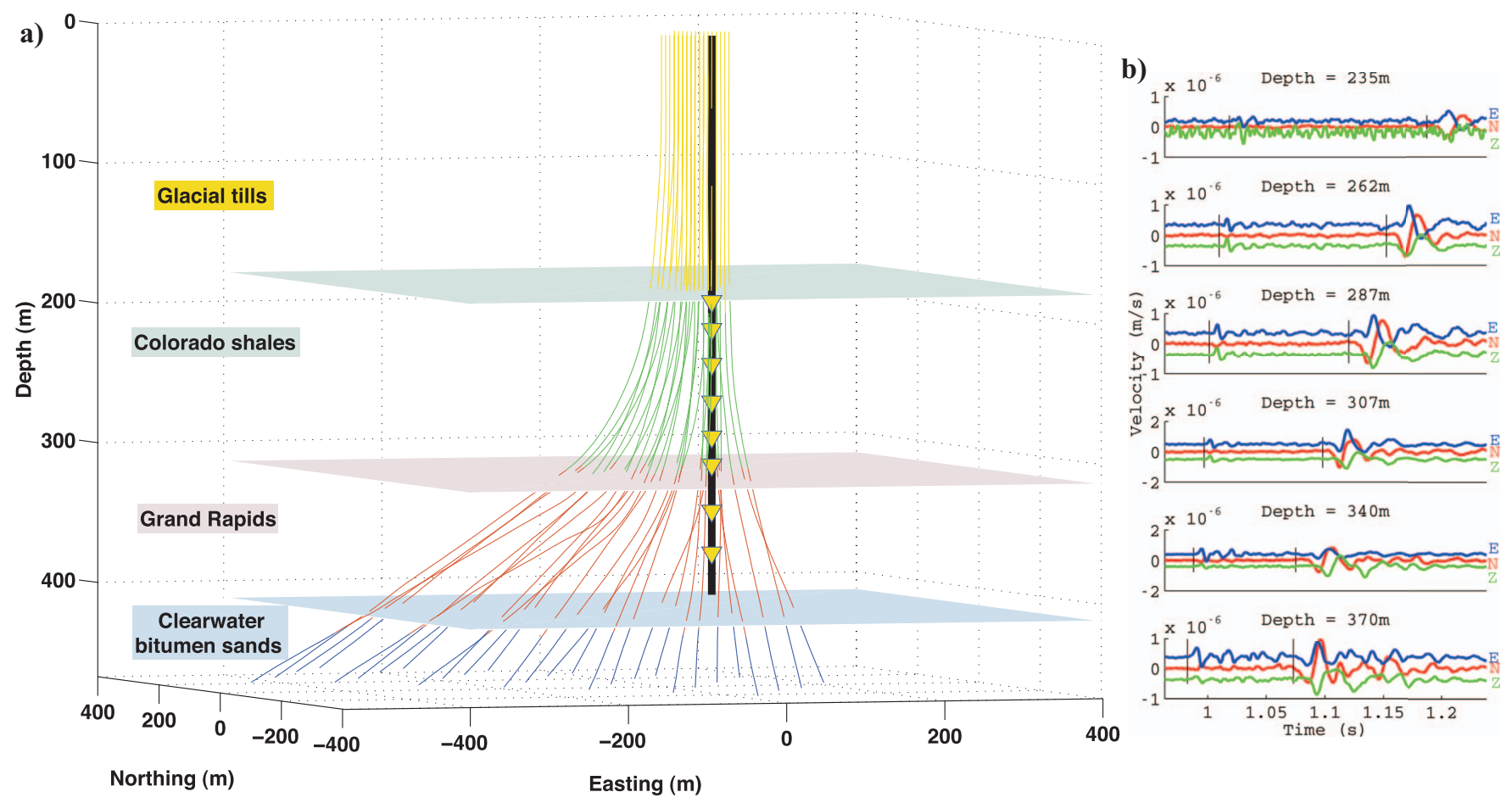

Figure 1. (a) Pad geometry at L08 pad at Cold Lake. A pad, or development unit, consists of one cemented passive seismic well (PSW) and several deviated steaming/production wells. The PSW has eight levels of 3-C geophones that record the microseismicity. The tops of different lithologic units are marked in color. (b) Velocity waveforms showing the N-, E-, and Z-components of data recorded on four geophones at different depths in the monitoring well. 
velocity changes smoothly, to avoid hypocenters away from the boundary being artificially located close to the boundary. We performed synthetic tests with this code and confirmed that the modified program is sufficiently robust to obtain earthquake locations. We also tested the code to ensure that events actually located at a boundary were not affected by the smooth velocity change at the boundary.

a)
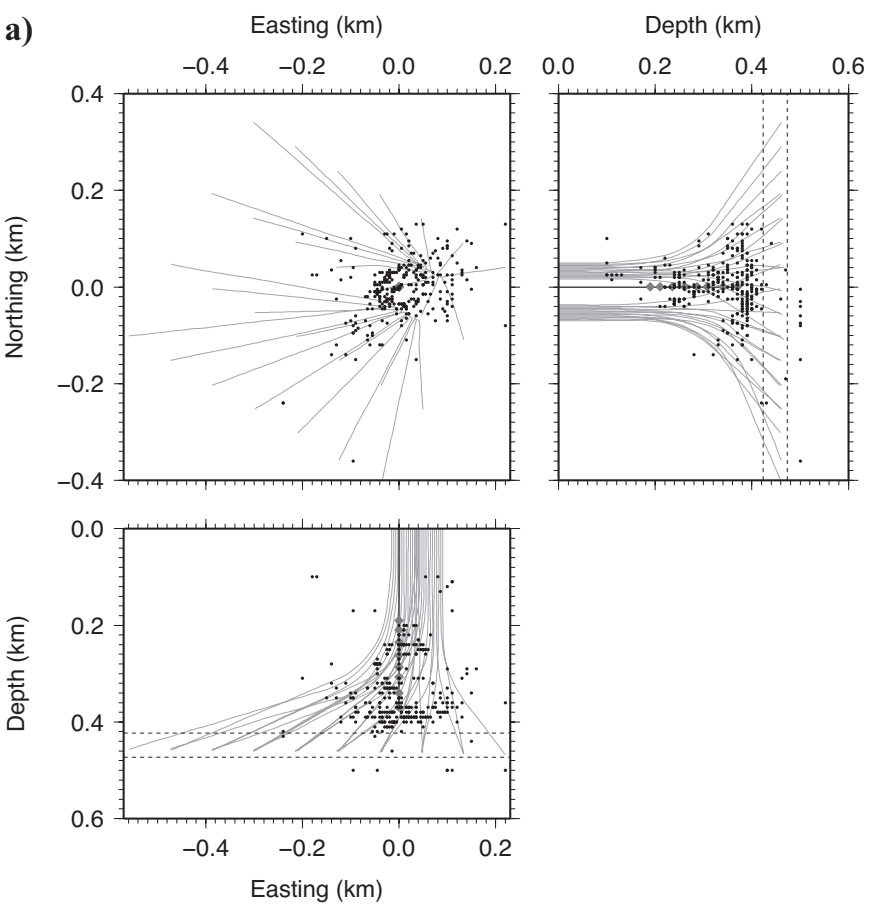

We updated the P- and S-wave velocity models and relocated the hypocenters iteratively. The initial P-wave velocity model is given by a compressional sonic log at the pad. Because the pad did not have a shear log, we computed an initial S-wave velocity model from the $\mathrm{P}$-wave model and the $V_{\mathrm{P}} / V_{\mathrm{S}}$ ratio observed at another pad. Hence, this initial $\mathrm{S}$-wave model may not represent the velocity before

b)

b)

Depth $(\mathrm{km})$
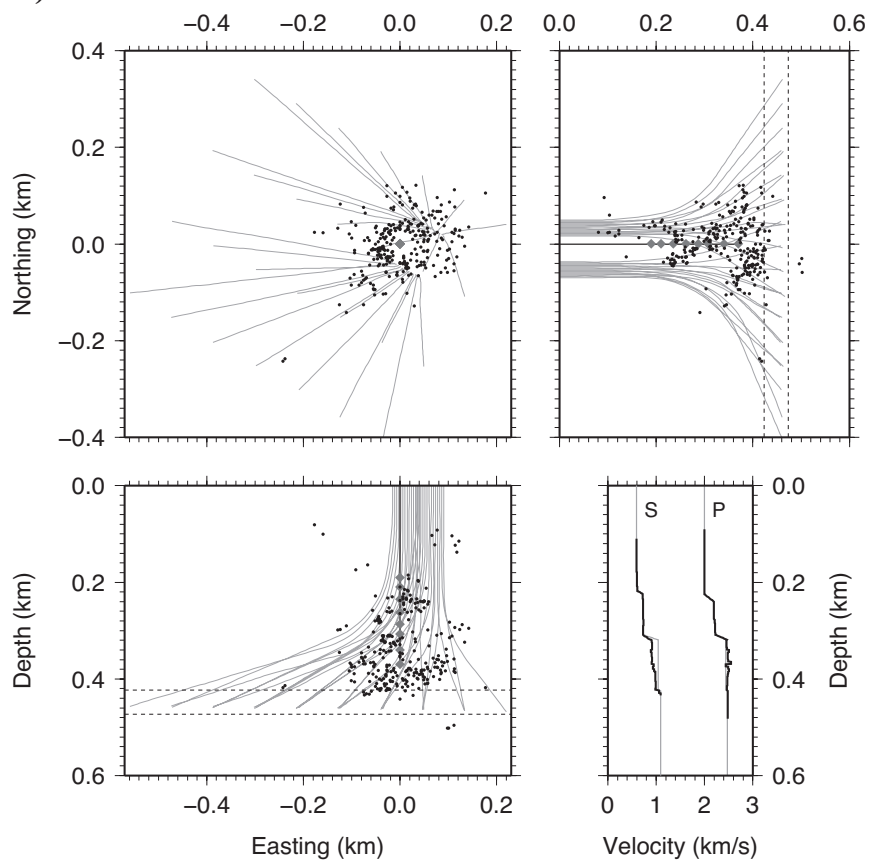

c) Easting $(\mathrm{km})$
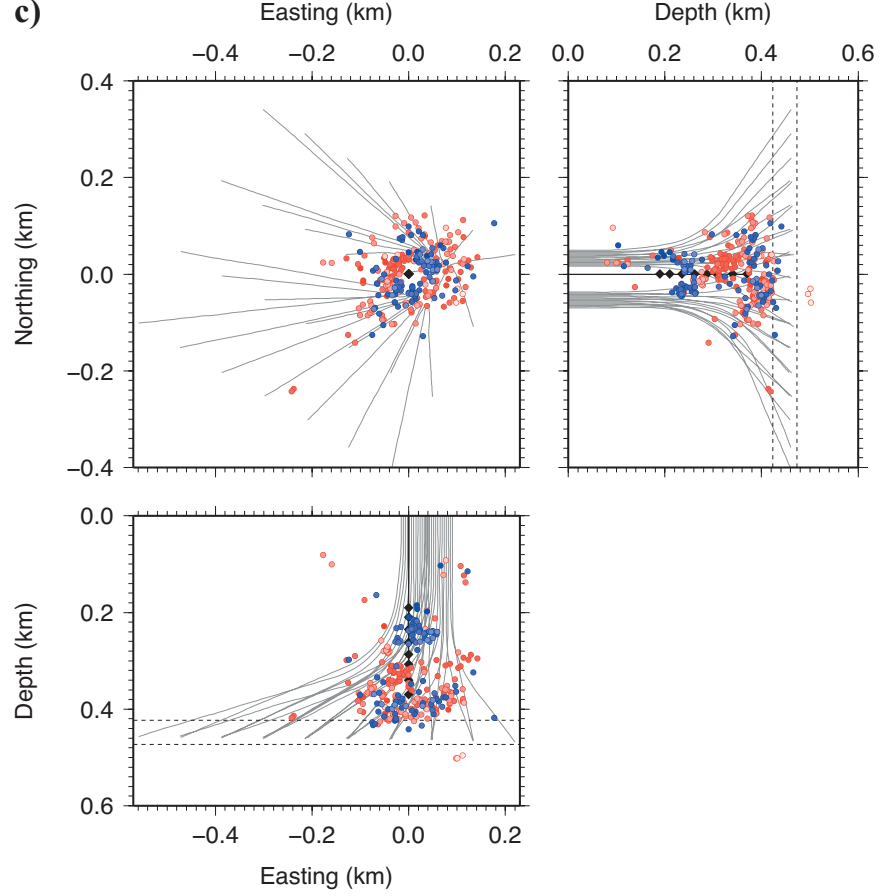

Figure 2. Locations of microearthquakes (a) before relocation, (b) after relocation, and (c) during cycle 1 (red) and cycle 2 (blue). (c) Dark and light colors show early and late events in the cycle, respectively. Three windows show the projection of the hypocenters (solid circles) and injection/production wells (gray lines) onto a horizontal plane and two orthogonal vertical planes. The zone between the two dotted lines shows the oil reservoir. The dark vertical line from the origin is the observation well (PSW) along which eight geophones are shown by diamonds. P- and Swave velocity structures are shown in the right bottom portion in (b). The gray line is the initial model and the solid line is the final model. 
steam injection. We first relocated the events using the DD method and the initial $\mathrm{P}$ - and $\mathrm{S}$-wave velocity models. Then the new hypocenters were used in a 1D traveltime tomography to improve the velocity model.

We considered only a $1 \mathrm{D}$ velocity structure because this region is well represented with horizontal layers and has little lateral heterogeneity, and the microearthquakes used for traveltime tomography are vertically distributed. The subsurface was divided into 5-m-thick layers, in each of which velocity perturbations were obtained. When the velocity variations are large, it is preferable to invert for the velocity in thin layers, rather than use a smooth structure parameterized at a limited number of depths (Miyazawa and Kato, 2004). The improved velocity structure was used again to relocate the events. Iterations of relocation and traveltime tomography were used to reduce the traveltime residuals of $\mathrm{P}$ - and $\mathrm{S}$-waves, whose average values are improved from -1.86 and $12.35 \mathrm{~ms}$ before relocation, to -1.10 and $6.76 \mathrm{~ms}$ after relocation, respectively.

\section{Results}

The spatial distribution of microearthquakes before and after relocation and the spatio-temporal distribution are shown in Figure 2a-c. The refined velocity models are indicated in Figure 2b; 278 hypocenters are accurately relocated in Figure $2 b$. This number is less than the initial number of events because the DD method requires a cluster of neighboring event pairs, yet some initial events do not belong to any cluster. Compared with the distribution before relocation, event distribution in the clusters becomes clearer.

The lateral extent of the seismicity increases with depth as the production wells fan out with depth. The horizontal projection shows a cylindrically symmetric distribution, and the event distribution seems to be similar to the distribution of the production wells. The improved spatial errors in the event locations estimated from the synthetic tests considering noise are less than $10 \mathrm{~m}$ (less than about $5 \mathrm{~m}$ in horizontal and less than about $3 \mathrm{~m}$ in vertical) after the relocation, and the uncertainty in the locations because of the finite wavelength and limited acquisition geometry is negligible compared to the uncertainty caused by errors in the waveforms. However, the well bores are less than $20 \mathrm{~cm}$ in diameter, so we cannot always isolate a single well as being the well closest to the rupture.

Seismicity as a function of depth and time, and a histogram of events as a function of depth are shown in the top of Figure 3. We did not analyze any seismic data in the shaded intervals because there were no continuous data available. The seismicity increases with depth and peaks at a depth of about $400 \mathrm{~m}$, just above the oil reservoir. In the second cycle, we observe another seismicity cluster at a depth of about $230 \mathrm{~m}$ (shaded histogram). These features can also be seen in Figure 2. Many events in this shallower cluster have wave

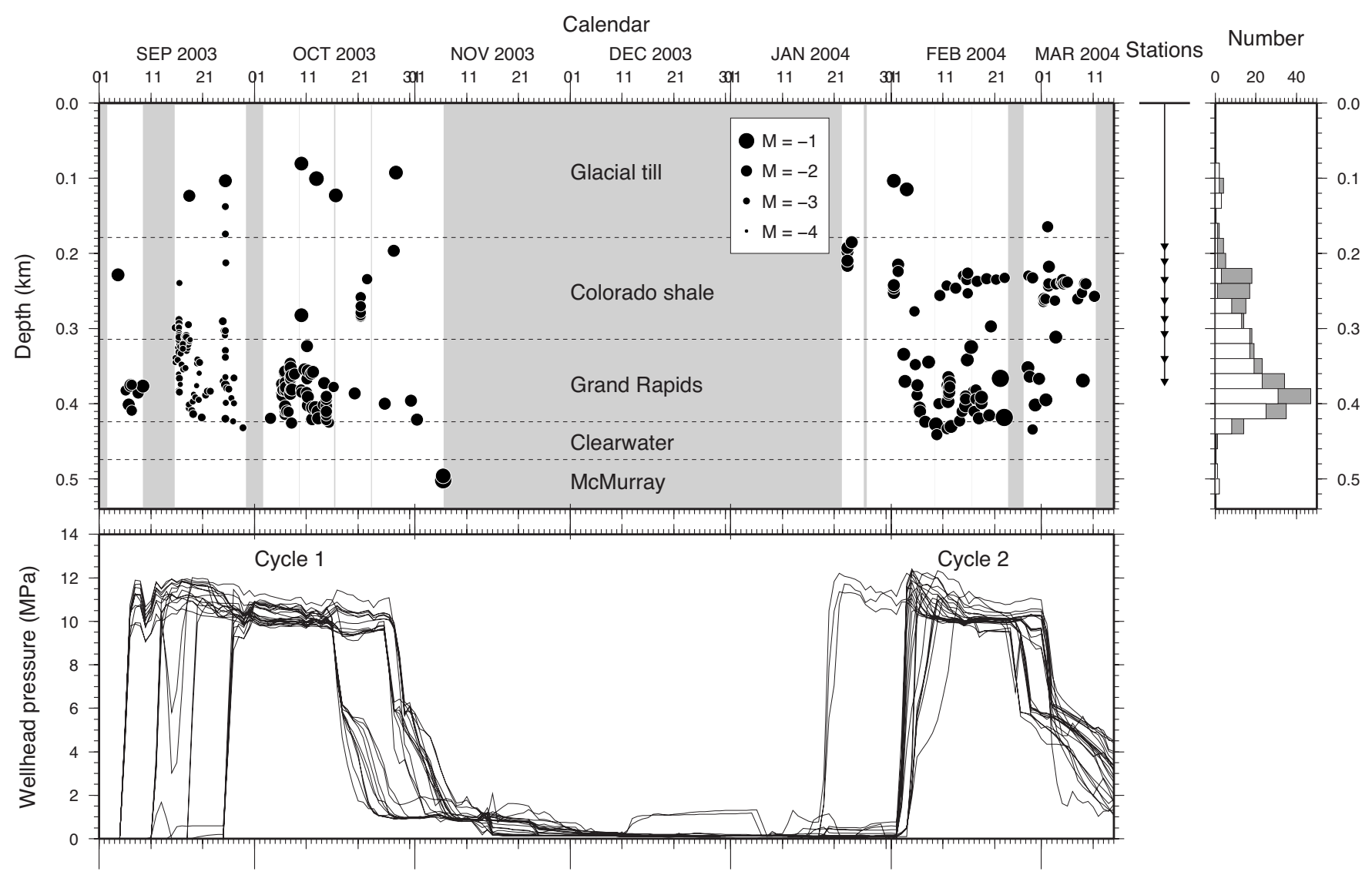

Figure 3. Event distribution as a function of time and depth (top left) between 1 September 2003 and 15 March 2004. In the shaded periods, passive seismic data are not available. The event magnitude is indicated by the circle size. The name of the formation at each depth between broken lines is printed. Heavy oil is located in Clearwater formation. In the right portions, station depth is illustrated as a reference, and the histogram shows the number of events for cycle 1 (white) and cycle 2 (gray) for different depth intervals. In the bottom, changes of wellhead pressures of 28 wells are indicated by lines. The high pressures correspond to steam injection. 
forms similar to each other, and suggest repeated events with similar magnitude.

We detected and located only a few large events in and below the oil reservoir. The oil reservoir may be an aseismic region, or the large distance (about $60 \mathrm{~m}$ ) between the deepest geophone and the top of the reservoir may have prevented smaller events from being detected by the sensors. The large attenuation of seismic waves in heavy oil at temperatures of about $150{ }^{\circ} \mathrm{C}$ (Behura et al., 2006) could also explain the small number of events observed in and below the reservoir. The largest events in the data set are located below the oil reservoir.

We may have underestimated the depths of these events by a few meters because velocities in the reservoir can be expected to drastically drop after steam injection (Behura et al., 2006). In the bottom portion of Figure 3, the pressure changes at 28 wellheads are indicated, where a high pressure corresponds to steam injection. On 25 September 2003, when steam injection started along seven wells on the northeast side of the pad, we observe a vertical event distribution along these wells, which suggests the presence of vertically propagating fractures.

The improved velocity structure in the right-bottom panel of Figure $2 \mathrm{~b}$ shows little velocity change for P-waves. Around the event cluster at a depth of about $400 \mathrm{~m}$, we observe a slight drop in the $\mathrm{P}$-wave velocity with depth. The improved $\mathrm{S}$-wave velocity model shows a significant reduction in velocity (about $100 \mathrm{~m} / \mathrm{s}$ ) at depths between about 300 and $400 \mathrm{~m}$, compared with the expected initial model.

The final model is consistent with the S-wave velocity estimated from seismic interferometry during the first cycle (M. Miyazawa, R. Snieder, and A. Venkataraman, personal communication). Because the velocity model represents laterally and temporally averaged values, we cannot use this model to infer that the velocity perturbations are caused by the fractures producing microearthquakes in the media. In an interferometric study, M. Miyazawa, R. Snieder, and A. Venkataraman (personal communication) also could not identify any temporal velocity changes caused by steam injection.

The final event locations are primarily controlled by the DD relocation method; the traveltime tomography scarcely changes the $\mathrm{P}$-wave velocity structure and does not significantly contribute to the relocation. S-wave data do not significantly affect the relocation because they are given lower weights causing the larger arrival time errors and fewer clean $\mathrm{S}$-wave picks as compared to $\mathrm{P}$-waves.

\section{STRESS ANALYSIS}

We found high seismicity for the region just above the reservoir during two cycles of steam injection, and another seismicity cluster at depth of about $230 \mathrm{~m}$ only during the second cycle. Because the seismicity is uniformly high in the deeper cluster, there may be additional forces and/or structural changes that cause the shallower seismicity to occur only in the second cycle.

Because of the unavailability of continuous seismic data during the production cycle, we did not analyze the seismicity or stress changes associated with production. It is possible that these stress changes explain the migration of seismicity to shallower depths, and that this migration may have started during production.

We explain the uniform higher seismicity for the region just above the reservoir using a simple geomechanical model. In the analyses, we neglect temperature changes.
There are two mechanisms to induce seismicity from steam injection. One is stress/strain changes associated with the reservoir expansion, and the other is pore-pressure changes in the overburden. Because only a small amount of steam penetrates the overburden, the effect of pore-pressure changes in the overburden is much smaller than the stress changes associated with reservoir expansion.

Casing failure events have a distinct signature (Talebi et al., 1998b), and can be isolated by careful inspection of event waveforms. We found only one candidate for casing failure in the catalogue. Most of the events are shear fractures and, hence, it is reasonable to assume that the rupture starts in the rocks surrounding the wells (e.g., Dusseault et al., 2001).

To model the reservoir appropriately, the initial stress field should be specified. From formation stress test measurements at wells at Cold Lake, the stress field in and above the reservoir is known. In the overburden, the maximum principal stress direction is along N30E$\mathrm{S} 30 \mathrm{~W}$, and the minimum principal stress direction is vertical and along N60W-S60E above and in the reservoir, respectively (e.g., Dusseault, 1980; Talebi et al., 1998c).

\section{Geomechanical model}

We calculate the displacement and strain changes caused by reservoir expansion using a fault dislocation model (Okada, 1992) in a 3D elastic half-space. The oil reservoir extends from depths of 424 to $474 \mathrm{~m}$. We model the expansion using a simple triangular pyramid-shaped region at the bottom of each injection well because, in the early CSS cycle, the reservoir is partially soaked with steam/ fluid at the bottom of the reservoir. Based on the volume of steam injected in the well, we determined that it is reasonable to use a pyramid with a vertical expansion of $50 \mathrm{~cm}$. The height of the triangle is $50 \mathrm{~m}$ and the two bases of the pyramid are 50 and $70 \mathrm{~m}$, respectively.

We align the long base along N30E-S30W because the increasing pore pressure facilitates preferential flow along N30E-S30W-oriented vertical fractures that are associated with the initial stress field. Because the expansion starts at the bottom of the well, we impose a larger expansion at the bottom than at the top. Because we are interested in strain changes in the region shallower than about $400 \mathrm{~m}$ and not in the vicinity of the expansions, the details of the pyramid structure do not strongly influence the overall stress pattern.

We use the same shape and size of expansion at the bottom of all 28 wells and calculate the displacement, strain, and stress changes in a 3D elastic half-space. Lame's constants, estimated from the $\mathrm{P}$ - and S-wave velocities and the density, are $\mu=1 \mathrm{GPa}$ and $\lambda=6 \mathrm{GPa}$.

Figure 4 shows a N60W-S60E vertical cross section at an observation well, with displacement changes in three coordinate directions caused by reservoir expansion. The $x-, y$-, and $z$-axes are positive across S60E, N30E, and vertical directions, respectively. Shaded triangles are the regions where we imposed expansion. Positive and negative displacement changes are indicated in red and blue, respectively. The values are large for regions close to the reservoir. The vertical displacement changes $u_{z}$ are significant compared with the horizontal ones, $u_{x}$ and $u_{y}$. The maximum vertical displacement change on the surface is $3.8 \mathrm{~cm}$.

Figure 5 shows the vertical cross section of the normal strain changes. The inline horizontal normal strain change $e_{x x}$ has a large negative value between neighboring expansions, associated with large compaction, whereas it shows horizontal dilation above and below the triangular expansion. The crossline horizontal normal strain change $e_{y y}$ shows expansion in this plane. Both above and be- 
low the triangular expansions, there is vertical compaction. In regions shallower than about $350 \mathrm{~m}$, the subsurface is vertically compacted and horizontally expanded. The volumetric strain change, $\theta$ $=e_{x x}+e_{y y}+e_{z z}$, is nearly one order of magnitude smaller than normal strain changes (Figure 6), which indicates that pore-pressure changes associated with the compaction of the overburden do not play an important role in triggering microearthquakes.

\section{Mohr's circle analyses}

A Mohr's circle represents a useful way of expressing and visualizing relationships between normal and shear stresses on planes (e.g., Jaeger and Cook, 1969), and can be used along with frictional failure criteria to determine failure planes.

The initial stress fields give the initial Mohr's circles at each depth. From the initial stress fields and the geomechanical model described above, we solve the eigenvalue problem to determine the three principal stresses, and the Mohr's circles for the perturbed stress after the deformation can then be calculated. The analyses are performed in a 3D space, although we do not show the intermediate principal stress. The Mohr's circles representing stress changes at depths of 200, 250, 300, 350, and $400 \mathrm{~m}$, before (black) and after (colored) expansion are shown in Figure 7. The colored areas indi-
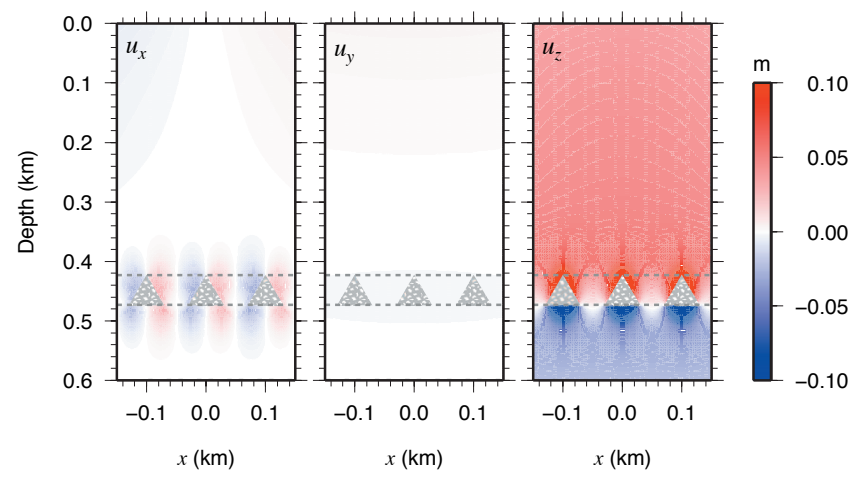

Figure 4. A vertical cross section of displacement changes close to the observation well caused by steam injection in the reservoir. The cross section is taken along N60W-S60E. The triangular expansions (shaded triangles) are located in the reservoir. The zone between the two dotted lines shows the oil reservoir. The inline and crossline horizontal displacement changes are represented by $u_{x}$ and $u_{y}$, respectively; $u_{z}$ is a vertical displacement change. Positive and negative changes are indicated in red and blue, respectively.
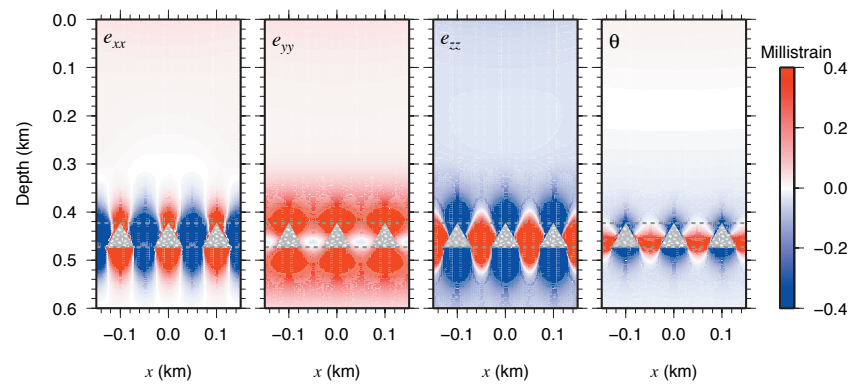

Figure 5. A vertical cross section of normal and volumetric strain changes; $e_{x x}$ and $e_{z z}$ are inline horizontal and vertical strain changes, respectively, and $e_{y y}$ is the crossline horizontal strain change; $\theta$ is the volumetric strain change. Dilated and compacted regions are indicated in red and blue, respectively. cate the collection of Mohr's circles for points in the horizontal plane at fixed depths. Because of the symmetry, we only show the upper half of the Mohr's circles.

\section{DISCUSSION}

To relate the stress changes to the seismicity, a failure criterion must be specified. We assume a Coulomb failure criterion with a coefficient of friction of 0.3 and a cohesion of about $0.5 \mathrm{MPa}$. These values are similar to those determined experimentally for sandstone (Dewhurst and Hennig, 2003). The Coulomb failure criterion for these values (gray dotted line, Figure 7), explains the increased seismicity at depth. The Mohr's circles in the shallower region (at a depth less than $300 \mathrm{~m}$; shown in blue) do not touch the gray line and thus little seismicity occurs at those depths. This is because there is significant vertical compaction and the calculated Mohr's circles (colored) fall inside the initial ones (black semicircles). Even at a

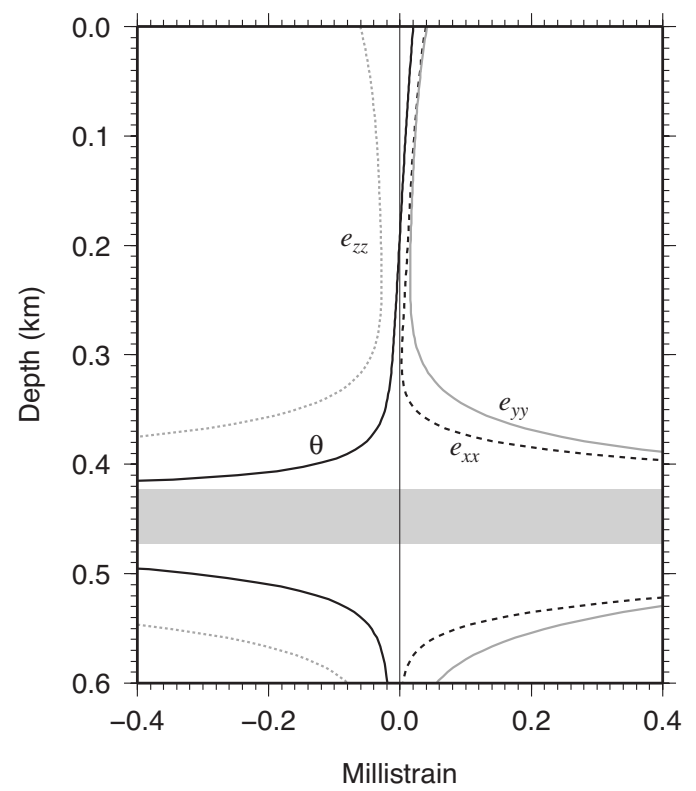

Figure 6. Strain changes as a function of depth. Horizontal normal strain changes $\left(e_{x x}\right.$ and $\left.e_{y y}\right)$, vertical strain change $\left(e_{z z}\right)$, and volumetric strain change $(\theta)$ at $x=0$ in Figure 5 are shown. The shaded region shows the oil reservoir.

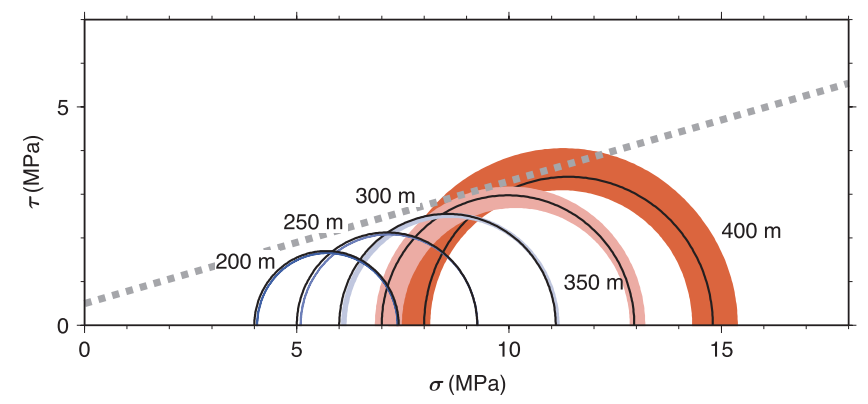

Figure 7. Mohr's circle changes caused by expansion. The initial Mohr's circles defined by the tectonics at each depth are indicated by solid semicircles. The Mohr's circles after stress changes caused by reservoir expansion are within the color regions. The gray dotted line is the employed Coulomb failure criterion with a coefficient of friction of 0.3 and cohesion of $0.5 \mathrm{MPa}$, respectively. 
depth of $400 \mathrm{~m}$, some of the calculated Mohr's circles fall inside the initial ones, but at several locations, there is enough stress change to cause an increase in the Mohr's circle radius (in red), resulting in failure and associated microearthquakes.

Similar high seismicity close to reservoir depths can also be achieved by assuming a friction coefficient of 0.20 to 0.32 and cohesion of zero to $1 \mathrm{MPa}$, and there is some nonuniqueness, but the values we used in this study are quite reasonable for the lithology of the region.

Our model does not account for the increase in the value and area of the reservoir expansions during steam injection nor the progression of injection from the southwest side to the northeast side of the pad. Despite these simplifications, the model can successfully explain the observed seismicity in the first steam cycle, and provides insights into the frictional controls on faulting in the region. Even if we substitute the pyramid with another shape such as a cylindrical one, similar results are observed.

The model, however, fails to explain the increased seismicity at a depth of about $230 \mathrm{~m}$ during the second cycle of steam injection. It is possible that lithologic variations play an important role in controlling the seismicity distribution because this depth is close to the velocity boundary in the Colorado shales (see velocity changes in Figure 2b), and the assumption of a homogeneous half-space in our geomechanical model may be too simple.

Temperature changes are also one of the most important factors that should be taken into consideration. A change in temperature can change physical properties, notably a reduction of friction coefficient, which may result in the excitation of microearthquakes. In the Mohr's circle analyses, this can be represented by the change of the friction criterion. The stress changes caused by reservoir expansion that trigger microearthquakes in Cold Lake are much larger than those for natural earthquake triggering (less than about $10 \mathrm{kPa}$ ), so we think it sufficient in this study to include only the expansion-induced stress changes and omit the temperature effect. This approach for addressing the occurrence of earthquakes is sometimes used for the migration of natural earthquakes caused by high-temperature magma penetration (e.g., Toda et al., 2002).

The analysis shown here recovers the distribution of source locations and event times. A more detailed analysis of the waveforms may help constrain the source mechanisms. This will provide information on the orientation of the failure planes, may help distinguish between casing failures and microseismic events in the host rock, and also help explain the stress field that causes the shallow seismicity in the second cycle.

\section{CONCLUSIONS}

We show that the DD method significantly improves the accuracy of induced micro-earthquake locations at Cold Lake. The analysis of seismic data acquired along the vertical monitoring well locates 278 microearthquakes with event magnitudes ranging from -4 to -1 . It highlights clusters of seismicity for the region at a depth of $\sim 400 \mathrm{~m}$, just above the reservoir, in successive steam cycles, and another seismicity cluster at a depth of $\sim 230 \mathrm{~m}$ during the second cycle. There are a few events in and below the oil-reservoir. The increased accuracy in spatial and temporal variation of seismicity is important for the detection of fluid incursion in the overburden shales. We also used the data to improve the 1D P- and S-wave velocity model of the region by traveltime tomography. The deep seismicity pattern observed in both steam cycles is explained using a simple 3D geome- chanical model and a Mohr-Coulomb failure criteria, with a friction coefficient between 0.20 and 0.32 .

\section{ACKNOWLEDGMENTS}

We thank Richard Smith and Colum Keith at Imperial Oil, Canada, and Jeffrey Bailey at ExxonMobil, URC, for sharing their knowledge about the field, data, and software, and Robert Raschke for helping us with data handling issues. We are grateful to Grant Gist at ExxonMobil, URC, for technical discussions and support of the project. We thank Mike Batzle at CSM for providing us with petrological insights into heavy oil. We thank the associate editor, Martin Landrø, and three anonymous reviewers for careful and thoughtful reviews.

\section{REFERENCES}

Ake, J., K. Mahrer, D. O'Connell, and L. Block, 2005, Deep-injection and closely monitored induced seismicity at Paradox Valley, Colorado: Bulletin of the Seismological Society of America, 95, 664-683.

Behura, J., M. Batzle, and R. Hofmann, 2006, Shear properties of oil shales: 76th Annual International Meeting, SEG, Expanded Abstracts, 1973 1977.

Brune, J. N., 1970, Tectonic stress and spectra of seismic shear waves from earthquakes: Journal of Geophysical Research, 75, 4997-5009. , 1971, Correction: Journal of Geophysical Research, 76, 5002.

Dewhurst, D. N., and A. L. Hennig, 2003, Geomechanical properties related to top seal leakage in the Carnarvon Basin, Northwest Shelf, Australia: Petroleum Geoscience, 9, 255-263.

Dusseault, M. B., 1980, The behaviour of hydraulically induced fractures in oil sands: Proceeding of the 13th Canadian Rock Mechanics Symposium, 36-41.

Dusseault, M. B., M. S. Bruno, and J. Barrera, 2001, Casing shear: Causes, cases, cures: June, SPE Drilling \& Completion, 98-107.

Earle, P., and P. M. Shearer, 1994, Characterization of global seismograms using an automatic picking algorithm: Bulletin of the Seismological Society of America, 84, 366-376.

Jaeger, J. C., and N. G. W. Cook, 1969, Fundamentals of rock mechanics: Methuen.

McGillivray, P., 2005, Microseismic and time-lapse seismic monitoring of a heavy oil extraction process at Peace River, Canada: Recorder, Jan., 5-9.

Miyazawa, M., and M. Kato, 2004, On interpolation functions in traveltime tomography: Geophysical Journal International, 158, 169-178.

Okada, Y., 1992, Internal deformation due to shear and tensile faults in a halfspace: Bulletin of the Seismological Society of America, 82, 1018-1040.

Parotidis, M., S. A. Shapiro, and E. Rothert, 2004, Back front of seismicity induced after termination of borehole fluid injection: Geophysical Research Letters, 31, L02612.

Shapiro, S. A., S. Rentsch, and E. Rothert, 2005, Characterization of hydraulic properties of rocks using probability of fluid-induced microearthquakes: Geophysics, 70, no., X, F27-F33.

Shapiro, S. A., E. Rothert, V. Rath, and J. Rindschwentner, 2002, Characterization of fluid transport properties of reservoirs using induced microseismicity: Geophysics, 67, 212-220.

Talebi, S., and T. J. Boone, 1998, Source parameters of injection-induced microseismicity: Pure and Applied Geophysics, 153, 113-130.

Talebi, S., T. J. Boone, and J. E. Eastwood, 1998a, Injection-induced microseismicity in Colorado shales: Pure and Applied Geophysics, 153, 95-111.

Talebi, S., T. J. Boone, and S. Nechtschein, 1998b, A seismic model of casing failure in oil fields: Pure and Applied Geophysics, 153, 197-217.

Talebi, S., S. Nechtschein, and T. J. Boone, 1998c, Seismicity and casing failures due to steam stimulation in oil sands: Pure and Applied Geophysics, 153, 219-233.

Toda, S., R. S. Stein, and T. Sagiya, 2002, Evidence from the AD 2000 Izu Islands earthquake swarm that stressing rate governs seismicity: Nature, 419, 58-61.

Waldhauser, F., 2001, hypoDD - A program to compute double-difference hypocenter locations: United States Geological Survey, Open File Report 01-113.

Waldhauser, F., and W. L. Ellsworth, 2000, A double-difference earthquake location algorithm: Method and application to the northern Hayward fault, California: Bulletin of the Seismological Society of America, 90, 1353-1368. 